\title{
Public-private entanglements: consultant use by local planning authorities in England
}

Article

Accepted Version

Wargent, M., Parker, G. and Street, E. (2019) Public-private entanglements: consultant use by local planning authorities in England. European Planning Studies, 28 (1). pp. 192-210. ISSN 1469-5944 doi:

https://doi.org/10.1080/09654313.2019.1677565 Available at https://centaur.reading.ac.uk/86672/

It is advisable to refer to the publisher's version if you intend to cite from the work. See Guidance on citing.

To link to this article DOI: http://dx.doi.org/10.1080/09654313.2019.1677565

Publisher: Taylor \& Francis

All outputs in CentAUR are protected by Intellectual Property Rights law, including copyright law. Copyright and IPR is retained by the creators or other copyright holders. Terms and conditions for use of this material are defined in the End User Agreement.

www.reading.ac.uk/centaur 
Central Archive at the University of Reading

Reading's research outputs online 


\title{
Public-private entanglements: consultant use by Local Planning Authorities in England
}

\author{
European Planning Studies
}

Matthew Wargent*, Gavin Parker and Emma Street

Department of Real Estate and Planning, University of Reading

\begin{abstract}
*Corresponding author. Address: Department of Real Estate and Planning, University of Reading, Whiteknights, Reading, RG6 6BL, United Kingdom. Telephone: +44 (0)118 378 5415. Email: $\underline{\text { m.war- }}$ gent@ reading.ac.uk.
\end{abstract}

\begin{abstract}
Despite intermittent recognition of the input of private planning consultants in the UK planning system, there remains a paucity of empirical studies into their roles and influence in contemporary practice. Drawing on interviews with both public and private planners in England, this paper explores the nature of the public-private entanglements that increasingly define local planning practice. These include the heterogeneity of the consultant market, the rationales employed to justify consultant use, the nature of the expertise being deployed, and the asymmetrical nature of public/private relationships. The paper argues that the demands made on the public planning system and the planners that operate it are driving teleological explanations of the use of private expertise, displaying an ambivalence to the fact that Local Planning Authorities are in a position of critical dependency with private sector consultants. In concluding, it is argued that the knowledges that underpin planning practices are increasingly shaped by the market, with the potential to undermine planning's public interest purpose.
\end{abstract}

Keywords: plan-making; local plans; private sector, consultants; consultocracy. 


\section{Public-private entanglements: consultant use by Local Planning Authorities in England}

\section{Introduction}

The privatization of planning practice in the UK has been explored intermittently within planning scholarship over the past three decades (Dear, 1989; Fordham, 1990; Higgins and Allmendinger, 1999; Audit Commission, 2006; Gunn and Vigar, 2012; Parker et al., 2018; Raco, 2018). However, despite their centrality to contemporary planning, private sector consultants themselves have historically been excluded from studies of professional practice (Linovski, 2019). Diagnoses of a 'hollow state' are well established, whereas the outsourcing of public service delivery to third parties is well documented (see Froud et al., 2017), while the role of private actors in providing technical expertise and policy input remains under-explored (Scott and Carter, 2019; Savini and Raco, 2019). Critical attention has therefore begun to focus on the contributions of consultants to the operation of the UK planning system (Parker et al., 2014; Raco, 2013; Raco et al., 2016; Parker et al., 2019; Wargent et al., forthcoming), and throughout Europe, including Ireland (Brudell, 2014), Germany (Vogelpohl, 2018), and the Netherlands (Grijzen, 2010), as well as globally including Australia (Steele, 2009), South America (Zanotto, 2019), and North America (McCann, 2001; Read and Leland, 2011; Momani and Khirfan, 2013; Linovski, 2016; 2018; 2019; Loh and Norton, 2013; Loh and Arroyo, 2017).

Recent contributions to this debate in the UK have explored the historical role of private sector expertise in the planning project (Inch et al., forthcoming), depicting the long-standing dynamic between public and private sectors which pre-dates processes of neoliberalization, but which has undoubtedly been intensified by it. Planning consultants have traditionally acted for private developers and within "liminal governance spaces between private markets and the formal planning system" (Raco et al., 2016: 218), but in recent decades are increasingly operating within the boundaries of the state itself, to the extent that local planning practice is increasingly defined by such public-private interactions (Parker et al., 2018). Since the late 1990s, consultant use by Local Planning Authorities (LPAs) has increased significantly, providing stable revenue opportunities for consultancy firms, with the market having diversified and expanded to meet those opportunities. This mirrors shifts witnessed across the 
public policy landscape, as consultants actively shape the ever-shifting organizational boundaries between public and private sectors (Ylönen and Kuusela, 2019).

This has raised concerns about consultants' impact on planning processes and outcomes, the accountability and democratic legitimacy of planning functions, and how and by whom the public interest is being maintained (Steele, 2009; Parker et al., 2014; Raco et al., 2016; Parker et al., 2018; Slade et al., 2019). Drawing on in-depth interviews with both public and private planners involved in plan-making in England, this paper demonstrates the extent and diversity of public-private interactions, and explores the increasing reliance of LPAs on private expertise. The empirical focus on plan-making at the local scale in England is an important one given that since 2010, successive administrations have established the local as the scale at which planning should take place (Lord and Tewdwr-Jones, 2014). Concentrating on the creation of planning policy is paramount as private actors now co-construct the regulations they are later subject to, as has been recognized in other national contexts (e.g. Linovski, 2018). Moreover as Newman (2014) points out the UK has tended to be typified as a symbolic marker of neoliberalization and local government has an integral role in 'mediating' such processes, underscoring the importance of understanding consultants and their interaction with public planning authorities in the English context.

Drawing on planners' frontline experiences, this paper makes several contributions to the growing understanding of the role and import of the private sector in planning. First, we stress the heterogeneity of the consultancy market in order to nuance analysis of private sector contributions, highlighting the diversity of actors involved in planning practice at time when planning is being 're-made'. Second, we suggest that LPAs have entered into a relationship of critical dependence with the private sector in ways that the existing planning literature has thus far only hinted at. Third, the findings suggest that many of the widely held assumptions concerning consultants and the consultant market are misplaced - notably, consultants' supposed independence of place and the downplaying of trust and existing relationships in market relations. Perhaps more significantly, although planning scholarship has long recognized the inherently political nature of planning, practitioners still stress the apolitical independence of external expertise, despite the political grey areas incorporated into private sector inputs. Further 
work is required to better understand how such inputs are then used by public sector clients and the political work undertaken. In concluding, the paper highlights a need to reassess of the governance of planning in a post-public era, as the local state - in a Polanyian sense - co-constructs the emergent markets of knowledge production. In order to do so there is a need therefore to move away from teleological explanations of private expertise towards greater consideration of what is driving consultant use and the political work undertaken through their inputs.

\section{The rise of the consultocracy in planning}

Nearly three decades ago, Hood and Jackson (1991: 24) coined the term "consultocracy" to denote the insinuation of consultants within the operational logics of public administration and governance. Since then, a wide and heterogeneous field of research has emerged, reflecting diverse practices of public service delivery and forms of public-private interaction. Unlike other forms of privatization - broadly taken here to mean the provisional or permanent passing of assets, services, and competencies from public to private hands - the defining characteristic of the consultocracy concerns how private knowledge is placed "deep into the heart of how societies are ruled and governed", even so far as to become essential to the functioning of democratic governance (Ylönen and Kuusela, 2019: 242).

The size of the planning consultant market in England, the types of work undertaken, and the claims to knowledge made by the private sector have shifted significantly throughout the post-war period. Until the 1990s, the consultancy market expanded and contracted loosely in relation to the status and ambit of public sector planning. By the turn of the century private sector activity reached into more aspects of the planning process, creating long-range plans and strategies, designing and implementing public engagement strategies, providing technical studies and undertaking development control functions ${ }^{1}$. This coincided with a series of now well-worn attacks on the performance of local government, many of which have been motivated by neoliberal assumptions. The wider marketization of the public sector

\footnotetext{
${ }^{1}$ Private actors, particularly larger consultancies, also play a significant role in shaping the planning system not only through practice, but through governmental policy reviews, involvement in influential committees and reports and through lobbying activity.
} 
has refashioned conceptions of public service towards more 'businesslike', managerial approaches under the guise of Public Choice Theory and the New Public Management (Diefenbach, 2009; Birch and Siemiatycki, 2016). The impacts of such reforms vary in intensity depending on local political structures, although in cases where reform is either encouraged or lightly contested, it has resulted in a weakening of control by politicians over the civil service and democratic decision-making processes (Christensen and Laegreid, 2001; Saint-Martin, 1998).

Consultant use gained significant momentum across the public sector during the 1980s (Saint-Martin, 2000) and planning was not exempt as posts in planning departments were increasingly taken on by temporary staff and private contractors (Fordham, 1990; Higgins and Allmendinger, 1999). Reforms inspired by the New Public Management reforms and the use of private sector capacity have proved mutually reinforcing (Savini and Raco, 2019), as public authorities replicate private sector approaches such as project-based working that tesselate with corresponding shifts towards contractualism. In this sense, managerial reforms in planning and urban governance have "co-evolved" with the expansion of specialist consultants (Raco et al., 2016: 211). One consequence of the steady elision of the distinctions between public and private realms, has been the tendency within the consultocracy literature to represent consultant use "as an inevitable outcome of the growing complexity and pace of our world", that is, as a response to turbulent policy landscapes rather than actors central to the reproduction of complexity and turbulence (Prince, 2012: 196), even as they service the system they have helped (re)shape.

Planning scholarship has been slow to acknowledge the rising influence of the private sector. It is often held that planning's unique blend of legal, administrative, bureaucratic, political/policy responsibilities acts as a natural break on privatization processes, creating a conventional wisdom that planning was one of only a "handful of local functions not contracted out or privatised" (Allmendinger, 2016: 20). Such a view is arguably a result of the long and complex role of the private sector in the gradual development of the profession in the UK (Inch et al., forthcoming), yet it is precisely the "range of in- 
terpretations and judgements" involved identified by Allmendinger, that makes the influence of consultants so requiring of scrutiny. Although LPAs may be "reluctant" to outsource planning activities (Slade et al., 2019), they continue to do so, to varying degrees, across a range of planning tasks.

The increasing reliance of public authorities on external capacity and expertise, and the steady income streams this created, allowed the consultancy market to expand throughout the 2000s. The market simultaneously diversified into new fields of knowledge, and consolidated via acquisitions and mergers across the sector. This process created a number of large firms that emerged throughout the 2000s. These processes of expansion and diversification have allowed planning consultants to infiltrate all spaces and levels of the planning system in England. These roles have been categorized by Parker et al. (2019) as advocates (e.g. promoting sites for a developer, lobbying Central Government for policy reform, or creating and defending the policies and evidence base for plans); advisors (e.g. producing evidence providing policy alternatives for LPAs, producing Neighbourhood Plans for communities, or undertaking development management via outsourced arrangements); and scrutineers (e.g. legitimizing knowledge deliberatively via plan examinations, acting as planning inspectors ${ }^{2}$, or assessing the performance of LPAs via centrally commissioned policy reviews). A fourth role is also emerging, that of mediators: where consultants act as intermediaries between multiple LPAs within a wider housing market area, or between other stakeholders such as local communities and LPAs during the Neighbourhood Planning process (Wargent et al., forthcoming; Stapper et al., 2019).

The influence of consultants in the public sector has crystallized with the inception of an austerity agenda pursued by successive Conservative-led administrations since 2010. The stark financial landscape of local government in England that has resulted is now well recognized, as substantial budget cuts made in the wake of the Global Financial Crisis were particularly keenly felt at the local level,

\footnotetext{
${ }^{2}$ To be adopted, Local Plans must pass an independent examination that determines whether the plan has been prepared in accordance with legal and procedural requirements, and if it is 'sound' (tests of soundness are set out in the NPPF). The process is dealt with by the Planning Inspectorate, an executive agency sponsored by sponsored by the Ministry of Housing, Communities and Local Government (MHCLG) and the Welsh Government. The planning inspector considers the evidence provided to support the plan and any representations made by local people and other interested parties. Typically the examination will include hearing sessions which are held in public. The Inspector reaches a judgement about whether or not the plan should be adopted, typically making recommendations concerning necessary changes.
} 
with planning one of the least well-protected functions (NAO, 2018; see Table 1). Centrally-driven cuts have bolstered justifications for consultant use in a drive for cost-efficiency, whilst policy-makers' attempts to introduce new regulations as a means of control over planning serve to open up new markets and avenues of profit-generation for consultants, further strengthening the position of larger consultancies in particular just as planning departments have suffered disproportionately from central government retrenchment (Raco, 2018: 130-131). 
Table 1: Reforms to the UK planning system influencing consultant use since 2010

\begin{tabular}{|c|c|}
\hline Reforms & Impact on LPAs and Implications for Consultant Use \\
\hline $\begin{array}{l}\text { Central } \\
\text { government } \\
\text { retrenchment }\end{array}$ & $\begin{array}{l}\text { Total expenditure on planning functions fell } 14.6 \% \text { in real-terms from } £ 1.125 \text { billion to } £ 961 \\
\text { million (NAO, 2019). The reduction in total expenditure has been offset by an increase in income } \\
\text { received from planning activities increased by } 24.8 \% \text { in the same period (from } £ 419 \text { million to } \\
£ 523 \text { million), representing the increasing commercialisation of planning activity } \\
\text { Nonetheless, between } 2006 \text { and } 2016 \text {, there has been a } 15 \% \text { overall decrease in planners } \\
\text { employed by LPAs (NAO, } 2019: 11 \text { ), whilst the RTPI's membership profile morphed to reflect a } \\
\text { growth in private sector planners, with } 44 \% \text { of members working mainly in the private or third } \\
\text { sectors (RTPI, 2019) }\end{array}$ \\
\hline $\begin{array}{l}\text { Rescaling } \\
\text { planning }\end{array}$ & $\begin{array}{l}\text { The removal of regional planning outside of London (e.g. revocation of Regional Spatial } \\
\text { Strategies) has placed a renewed political importance on local planning, with greater import once } \\
\text { again been placed on Local Plans. Significant political pressure has been exerted on LPAs by } \\
\text { Central Government to keep produce plans in a timely fashion and keep plans up-to-date } \\
\text { The introduction of an amorphous 'Duty to Cooperate' - a soft measure that requires adjacent } \\
\text { authorities to 'engage constructively, actively and on an ongoing basis' on strategic issues has } \\
\text { placed greater strain on LPAs and created opportunities for privately produced evidence studies } \\
\text { The introduction of hyper-local statutory planning in the form of Neighbourhood Planning (see } \\
\text { Parker et al., 2015) has created a new arena of community planning for LPAs to contend with } \\
\text { opening a significant market for consultants work for communities and mediating between } \\
\text { communities and planning authorities }\end{array}$ \\
\hline $\begin{array}{l}\text { New regulatory } \\
\text { framework }\end{array}$ & $\begin{array}{l}\text { The introduction of National Planning Policy Framework (NPPF) (applies to England only) and } \\
\text { the simplification } 1,300 \text { pages of national policy down to less around } 60 \text { has provided market } \\
\text { opportunities for specialist consultants to supply advice on the latest guidance as LPAs struggle to } \\
\text { keep up with the pace of change (e.g. the recent emphasis placed on viability by MHCLG which } \\
\text { has produced it's own industry of viability consultants) } \\
\text { The introduction of the Housing Delivery Test (which sets out a standard approach to compare the } \\
\text { delivery of housing within each LPA over the past three years against the required amount) is one } \\
\text { example of a raft of managerial benchmarks against which LPAs are now measured, whilst } \\
\text { opening opportunities for consultants to produce housing need projections and represents also }\end{array}$ \\
\hline Deregulation & $\begin{array}{l}\text { Powers for piloting alternative provision of processing planning services (has been in force } 12 \\
\text { May } 2016 \text { but the necessary regulations have not yet been made) represent explicit attempts to } \\
\text { open up planning authorities to private sector providers and break the public sector's monopoly } \\
\text { over administering development proposals } \\
\text { The extension of Permitted Development Rights allowing various categories of development to } \\
\text { take place without the need for planning permission has further weakened LPAs abilities to } \\
\text { manage and create places } \\
\text { The Growth and Infrastructure Act (2013) allowed applicants for major developments to apply } \\
\text { direct to the Secretary of State (in practice a Planning Inspector), rather than the relevant LPA, } \\
\text { where the LPA has been officially "designated" by the Secretary of State for having a record of } \\
\text { poor performance in the speed or quality of its decision-making. Central Government's ability to } \\
\text { "designate" in this fashion was extended in relation to non-major applications by the Housing and } \\
\text { Planning Act (2016) }\end{array}$ \\
\hline
\end{tabular}


The reforms described in Table 1 have created a self-reinforcing cause and effect relationship with the rise of the governance paradigm. As relations are extended and deepened between public, private and the third sectors across new and rediscovered spatial scales in newly marketized and/or commercialized services, the evolving character of the (local) state increasingly requires their party inputs to legitimize its actions and fulfil statutory its planning functions (see for example Ormerod and MacLeod, 2018). In a context of rapid reform, prompted by the need to reduce revenue expenditure, and achieve greater efficiency in line with the NPM principles, the (local) state is typically presented as profligate, overloaded and ineffective (Grijzen, 2010), with consultant use justified by internal resource constraints and a lack of in-house capacity (Momani and Khirfan, 2013).

Mazzucato (2014) argues that a discursive battle that acts to promote particular assumptions about efficiency and change feature in debates over the role of the state in this context. This includes how the state maintains and creates new markets for private business to exploit. Yet the roles and influence of consultants are frequently overlooked in such debates - they are often seen as reservoirs of neutral expertise and their inputs as independent, technical artefacts, with the effect that they are seen as broadly apolitical actors. Mutually-reinforcing trends around performance management and austerity have thereby led to new assemblages of actors who influence policy and practice, aligning to translate their priorities into policy and then pursue their implementation (McCann and Ward, 2011) in processes that are often opaque and hidden from public scrutiny.

This is reflected in the extant planning literature which divulges a range of rationales for consultant use by public authorities. These include: cost-reduction (Mitchell, 1995; Higgins and Allmendinger, 1999); supply of specialist expertise (where it is impractical to retain such skills in-house) (Fordham, 1990; McCann, 2001; Audit Commission, 2006; Grijzen, 2010); supply of technical competence (Dalton, 1986; Loh and Norton, 2013) and high quality advice (Davoudi and Healey, 1990); a source of innovation (Davoudi and Healey, 1990); and as a source of independence and legitimacy - including insulation from political attack (Mitchell, 1995; Campbell and Marshall, 2002; Healey, 2007; Momani 
and Khirfan, 2013; Linovski, 2016). As such, the extant literature largely provides a teleology of expertise, analyzing the consultocracy predominantly from the perspective of the purposes it serves rather than its postulated causes. This undoubtedly contributes to the naturalization of their position within the (local) state and deflects attention from the causes of consultant use. In particular, the significant increase in evidentiary requirements witnessed under New Labour in the mid-2000s, specifically relating to the specialized evidence base of Local Plans and the introduction of the concept of 'soundness' by the Planning and Compulsory Purchase Act (2004) (Lord and Hincks, 2010), and the frequency of reforms to the planning system (Parker et al., 2018).

The rise of consultant use in planning has also been underpinned by a persistent set of beliefs that public and private sector planners possess different, if not contrasting, dispositions, professional ethics and ideological attitudes (Read and Leland, 2011; Loh and Norton, 2013; Wargent et al., forthcoming). This is despite periodic attempts to define a more fluid dynamic between sectoral actors and institutions (Brown et al., 2003; Audit Commission, 2006) and more recent explorations of, for example, how the financialization of firms employing planning practitioners is shifting planning practice ( $\mathrm{Li}-$ novski, 2019). Concern regarding the fluidity between sectors is certainly not new. Fordham (1990: 247) articulated the potential for troubling conflicts of interest where consultants operate for both developers and public authorities:

If the consultant, as is usual, earns most of his/her living from developers then the ... skill which is praised there is advocacy - allied to a complete lack of concern with the public interest. It could be argued that such an advocate is helping in the process of defining the public interest. That is true, but misleading if we are talking about the possibility of this consultant's doing work for local authorities as well. This role requires some capacity to take the public point of view, not merely helping to define it incidentally by acting in a profit-maximizing role.

Taking a more relational view, Reade (1987: 92) reflected on the shared subculture between public and private actors that can develop:

They will be likely to develop shared attitudes and values, shared perceptions of what is economically possible and socially desirable, and most significantly, shared beliefs as to what kind of development best promotes the 'public interest'. They will be constantly working out between themselves, in private, what seems best for the 'community', rather than following standards and objectives imposed upon them as a result of open political debate and formal decisions reached by democratically elected representatives. 
Such a view recognizes the necessity of shared meanings, notwithstanding the complicated interrelations that are constantly made and remade in everyday planning practice. Understanding how 'the art of the possible' is co-constructed in this way is central to understanding the influence of private actors on public practice. This requires recognizing consultants as sociologically complex policy actors with professional and personal values. In this vein, Zanotto (2019) has explored forms of detachment deployed by planners to navigate their work, such as employing a deliberately narrow view of their inputs as a "technical service" divorced from its socio-political implications. This arguably helps facilitate processes by which the integration of consultants within governance arrangements can result in a tendency to curtail local democracy as part of a series of tactics used to substantiate consulting-driven strategies and render other voices (notably citizens) mute (Vogelpohl, 2018).

In the wake of these concerns critical attention has turned toward the ability of private sector planners to shape and deliver the public interest (e.g. Loh and Arroyo, 2017; Slade et al., 2019; Inch et al., forthcoming) as the market increasingly acts as the arbiter of the public interest by resolving conflicting and pluralist conceptions of the 'good' via the pursuit of economic activity and profit (Jordan, 1989; Tait, 2016). The motivations, dispositions and ethics of consultants, how they react to planning 'dilemmas' and competing interests, and their everyday practice, must therefore be closely considered - yet such questions remain largely unanswered (Raco et al., 2016). The remainder of this paper seeks to shed light on these issues, exploring the extent and diversity of public-private interactions, and given the increasing reliance of public planning authorities on private expertise in England.

\section{Methods}

The paper draws on primary data collected via 32 semi-structured interviews with professional planners in England between 2016 and 2018. Interviewees were split between public $(n=17)$ and private $(n=15)$ sector employees, although a significant minority had experience of working within both sectors. Analysis of the data showed significant consensus between public and private interviewees on the vast majority of issues (disagreements are highlighted in the findings below); throughout the findings 
that follow, consultant voices are prioritized as they have traditionally been overlooked in studies of planning practice. The empirical focus was kept to role of the private sector in the plan-making process. Although spatial planning extends beyond regulation of future land use to encompass attempts to influence economic, social and political aspects of space and place, Local Plans have taken on renewed political importance in England since 2010. All public sector interviewees therefore had experience of assembling one or more Local Plans post the introduction of the NPPF in March 2012, and all private sector interviewees had direct experience of aiding LPAs in this process. Private sector interviewees were drawn from: multinational, multi-disciplinary firms $(n=2)$; large, nationally-based firms of over 50 employees $(n=5)$; medium-sized firms of between 10 and 50 employees $(n=3)$; and soletraders with or without a small network of associates $(n=5)$. All interviewees were asked to reflect on their experiences on the plan-making process, focusing on the production and interpretations of evidence, the nature of public-private interactions, and the risks and rewards of consultant use.

Interviewees were recruited via a snowball sample starting from the researchers' existing contacts. Other than relevant work experience, no further restrictions were placed on the sample, although in practice the majority of interviewees were working in London and the South and South East regions of England. A sample of this size cannot claim to be representative, yet even a partial picture of contemporary practice represents a redress to the current lack of understanding of how private and public actors operate together in a client-contractor relationship. All identifying details of the interviewees and their places of work have been anonymised. The data were coded using electronic qualitative analysis software and analysed thematically.

\section{Public-private entanglements in plan-making in England}

Although consultants feature throughout the English planning system, these findings focus on their role in the production of Local Plans - a statutory planning document that sets out a framework of strategic priorities for future development within a Local Planning Authority's (LPA) jurisdiction. Inter- 
viewees reflected that the need to produce robust Local Plans in a timely fashion has undoubtedly contributed to LPAs' need for external capacity and expertise, however this is far from the only contributing factor. A number of public planners noted that increased evidentiary requirements could be traced back to New Labour's 'modernisation' project and its focus on evidenced-based policy, whilst the shift from land-use to spatial plans in this period also significantly expanded the types and range of evidence sources required. This increase in planning's ambit provided significant market opportunities for planning consultants. Nonetheless, analysis by the Royal Town Planning Institute reveals a more marked trend of the public sector shrinking and the private sector growing dating to 2009-10 (RTPI, 2019: 13-14), suggesting that planning has seen a step change in the composition of the profession during the post-2010 Conservative-led administrations (see Table 1):

In [our region] there are a lot of experienced officers who have left the public sector and moved into the private sector - like myself - and you tend to find that there isn't the expertise coming through so it leaves a bit of a vacuum, a bit of a void in terms of expertise and LPAs are undoubtedly relying more on the private sector because of it, to get evidence (Consultant Interview 4, sole-trader/small firm of associates)

The movement of planners from public to private sectors in this context is not new (Brown et al., 2003; Audit Commission, 2006). However the confluence of the increased need for evidence, nearconstant planning reforms and resource constraints in local government have created a self-perpetuating dynamic whereby the increasing scope and complexity of knowledge required to create plans drives demand for external consultants. This in turn provides more varied and attractive employment opportunities in the private sector that further hollows out the local state by eroding its practical knowledge.

\section{Heterogeneity and dynamism}

In recent decades the planning consultancy market has evolved via the twin processes of diversification and consolidation. Typically, small firms specialise in particular areas of expertise, before larger firms acquire them, subsuming their expertise into a more comprehensive 'offer' to LPAs and other clients. Both public and private interviewees stressed the significant variation in 'types' of consultants, 
marking distinctions between: areas of expertise - from specialists (e.g. operating solely in areas such as housing or retail studies) to "one-stop-shop" firms able to provide a range of services; client-base (i.e. whether a firm was working primarily for public or private clients, or both, as often is the case with larger firms); and the "ethos" or "purpose" of the firm. This last characteristic was a repeated theme throughout the interviews, and was central to how individual consultants framed their careers. Firms' ethos was also important to LPA planners, who recognized that "everyone knows you're going to get a different service from a multinational firm that maybe wasn't historically in planning, versus a specialist who is maybe more concerned with their corner of the profession" (LPA Interview 3).

Given that consultants play an increasing role in shaping the regulatory landscapes in which they themselves operate, there is a need for greater clarity and specificity about make up of the consultant market. The consultocracy literature acknowledges the the dynamism of the market and its ability to service public sector requirements, but tends to overlook the types of firms involved. Presenting the private sector as homogeneous, obscures the diversity of the market including the motivations and practices of individuals and firms. The "real mix" (Consultant Interview 3, sole-trader/small firm of associates) found within the planning consultancy market means that seeking to define consultants' contributions to planning or to typify public/private interactions is problematic. Just as a diverse range of working cultures exists within the public sector, so consultancies vary in their working cultures, thereby making generalizations about private realms at least partially disingenuous. This is compounded by fact that not all consultants working in planning are 'planners'; this fracturing of the profession is reflected in the RTPI's (2019: 15) estimation that there are 3,100 public sector planners and 2,700 private/third sector planners currently operating without professional accreditation from the RTPI.

Interviewees made a distinction between "boutique" consultancies - typically local or regional firms, and/or those specializing in one field of expertise such as retail studies or environmental consultancy and the larger, often multinational, firms, where planning services are typically one field within which the firm operates. The latter are able to "hoover-up contracts" (Consultant Interview 14, soletrader/small firm of associates) due to their size and reach (see Linovski's (2019) work on global 
"megafirms"). Small and medium consultancy firms were more likely to claim some variation in the public interest as a motivation, for example, co-opting discourses around the housing crisis to justify their work in assessing housing need, or working "on behalf of marginalised groups" (Consultant Interview 15, medium-sized firm) through their inputs. A number of private sector interviewees claimed to be delivering the public interest by looking beyond the increasingly short-term goals of public planning authorities:

We are able to do the long-term and strategic thinking that LPAs simply can't do under their resource constraints ... we're able to look ahead, see what the wider issues are in relation to particular areas of housing need for particular populations, consider what the [central] government might do next (Consultant Interview 15, medium-sized firm)

The same respondent reported multiple occasions where they had pressured public planning authorities to uphold the rights of protected groups under equality legislation. References to such 'public' values such as inclusion and strategic thinking expand the ambit of consultants' contributions beyond compartmentalized tasks and co-opt the traditional role of state bureau-professions as experts required to shape the public good (Clarke and Newman, 1997). This opens up questions concerning the independence of consultants as simple receptacles of objective evidence - which interviewees indicated remains a central justification for external expertise - and the political work undertaken by their advice and evidence, as the following response demonstrates:

... [I have just produced a] commercial assessments report [that] basically looks at a number of sites, there's one site in there ... that's better than all the other sites in terms of how it performs on employment type, and then the Council have effectively ignored that and allocated other sites rather than [basing it] on their own evidence base. Their hook for doing so is that they are caveats throughout my report that makes reference to the Council making a judgement call balancing up other factors ... Therefore the consultants will probably save face and the Council's get their wiggle room. So that's for me a technical example of how these things can be drafted if you're to allow both parties sufficient flexibility (Consultant Interview 2, sole-trader/small firm of associates)

Although variations on "wiggle room" were repeatedly posited as a necessary space of flexibility between the evidence base and the subsequent plan, interviewees were also conscious that this could be manipulated in a way that was less than transparent:

We have at least one LPA that's got a one-man-band consultant in drafting their Local Plan ... it's very clear they are being shown up a path that I would suspect most other 
consultancies, at the examination of the plan will be saying something very different ... I think that's part of the reason why probably LPAs do go to smaller companies because ... arguably they're easier to manipulate in terms of giving them more politically sensitive responses (Consultant Interview 12, large, nationally-based firm)

Despite the drive towards evidence-based policy and a rational approach to policy-making, the political work undertaken within the plan-making process, involving both public and private planners, remains a blackbox. Professional expertise has always had to contend with political considerations, however the introduction of non-state actors into policy creation opens up the possibility of conflicts of interest, but also further obscures the political work of planning behind ostensibly technical inputs.

\section{Trust and on-going relationships}

Both public and private interviewees also cited knowledge of the local context as a key rationale of the use of particular consultants, for example about local housing market:

We have been working with [City Council A] since about 2012 when we originally prepared a Strategic Housing Market Assessment. We then went on in 2013 to prepare a SHMA for [a neighbouring District Council] ... I have also worked with both councils, regarding their Local Plan Core Strategies, a Green Belt Business Park proposal that straddles the boundary between the two. So you can understand the relationships and tensions between those issues as well as potentially between the two authorities. ... we understand the pressures from the city but also from some of its neighbours. and how the two interrelate. Another consultant coming in either wouldn't know that, or would have to learn (Consultant Interview 5, large, nationally-based firm).

In instances such as this, consultants have acted as mediators between LPAs who have a Duty to Cooperate to address strategic planning matters, incorporating local knowledge and boundary spanning as part of their 'offer'. Some consultancy firms, often smaller outfits and regional offices of larger firms, are therefore more embedded in local places than the expert-outsider model typically presented. Both public and private interviewees expressed the view that larger firms were less dependent on reputation due to their reach and position as market-leaders, whereas smaller firms relied on local networks, word-of-mouth, and repeat custom. Larger firms could "get away with farming the work out to a graduate or an intern, and then have a director sign it off - but because it comes from a big name it's assumed the work is going to be alright" (Consultant Interview 10, medium-sized firm). The result being 
that consultants from small and medium sized firms were more likely to foster ongoing relationships with LPAs:

We select those LAs based on long-term relationships with them ... The choosing of those authorities is not very scientific; it tends to be about where we have personal relationships with decision makers ... it is very much based on individual relationships within the team (Consultant Interview 1, medium-sized firm)

By fostering on-going relationships, private actors are, temporarily at least, invited across a discursive and ideational threshold while being retained by the public client. Developing mutual trust during the plan-making process was a key concern for both LPA officers and consultants, which should not be surprising given that planning remains a "quite small ... incestuous profession" (Consultant Interview 4, sole-trader/small firm of associates). In this vein, public planners explained that consultants with whom they had established relationships were more likely to be awarded tenders than "unknown quantities" (LPA Interview 10) as they seek to retain control over the plan-making process.

A number of interviewees discerned a shift in attitudes between early career and more established professionals, indicating that "old school" scepticism towards the private sector was the exception rather than the rule:

I've always had really good relationships, I see planning as all of us working together ... I had to pick somebody up on this, someone who's quite senior recently at a meeting because they just had this in built distrust of the private sector ... there's this very old school view that you're on the dark side and I found it quite a shock to come across that in this day and age (Consultant Interview 6, multi-national firm)

'Traditional' concerns, for example around conflicts of interest (see Fordham, 1990), appear therefore to be less apparent or less problematic for planners entering the profession at a time when consultant use is more commonplace and thereby normalised.

\section{Resilience and dependency}

The value placed on consultants' local knowledge and existing relationships appears to belie the frequent concern that local government commissioning processes are preoccupied with cost-saving to the 
exclusion of other factors, as informal networks and trust clearly shape public-private interactions.

Formal commissioning can be circumvented through a process of 'chaining' successive, smaller contracts rather than recognizing the work under a single larger contract that meets the minimum requirement for a formal tendering process. This allows "productive relationships" to be maintained without having to "jump through the hoops" of commissioning (LPA Interview 15). Production of a Local Plan's evidence base requires multiple studies and frequently updates to past studies, for which the commissioning LPA simply returns to the same consultant. The need for updates might be the original study being rendered out of date by new regulations or simply the passage of time, or the study being affected by other portions of the emerging evidence base:

I often sit in examinations and its accepted round the table that we're trying to rely on evidence base that's three or four years old now - so the outcome of four or five examinations I've been to in recent months has been for an immediate review of [our study] ... essentially planning inspectors are saying to the councillors you need to appoint [the interviewee] and his company to update your assessment (Consultant Interview 15, medium-sized firm)

Such path dependent relationships were largely considered a strength of the public-private dynamic, for the reasons of trust and control discussed above. Moreover the uneven and unpredictable workloads required during the plan-making process are well-serviced by the short term contracts on offer, affirming classical characterizations of the private sector as more flexible than state bureaucracies and more able to react to the exigencies of the planning system. The danger of such a view is to reify the planning system as a machine, 'something out there', into which private actors merely plug their technical inputs, rather than a co-constructed set of practices that are constantly (re-)constructed by multiple actors. Nonetheless, the flexibility of the consultancy market allows firms to react quickly where fields of expertise shift depending on the latest governmental reform and to anticipate shifting trends (see the "long-term and strategic thinking" that some consultants seek to provide). The majority of LPAs interviewed noted that consultants provided essential expertise and capacity that is regarded as impractical to retain permanently. This arguably adds resilience to the planning system as a whole by serving gaps in local government knowledge in ways unacknowledged by the wider literature:

It comes down to capacity ... Local Authority officers are under a lot of pressure, under capacity, under trained, it worries me actually, local government. There's some brilliant 
planners in local government, I'm not generalising, but also I'm coming across a lot of Local Authorities that lack, have big gaps in their expertise and knowledge (Consultant Interview 7, large, nationally-based firm)

Resilience is also added in less obvious ways: one consultant suggested they were acting as "the institutional memory" (Consultant Interview 15, medium-sized firm) given the staff turnover in one LPA. Although some consultants framed their inputs as adding resilience to the planning system in this way, such a dynamic points to a growing asymmetry between public and private skillsets, the consequences of which are as yet unknown.

In some specialist areas of evidence production LPAs are locked into a dependent relationship with a small number of consultants who have effectively cornered the market. Such forms of quasi-monopoly contradict the classic language of markets concerning competition-driven efficiency, and can lead to sub-standard advice, selective or distorted information, excessive pricing, and even external experts advocating policies deliberately designed to increase the demand for the consultants' services (i.e. rent-seeking). None of the interviewees in this study believed such practices were prevalent in the English planning context, but such dependency highlights how consultocratic forms of planning introduce unknown motivations into public policy. Just as problematically, both public and private planners acknowledged that the effects of austerity had undermined the ability of LPAs to interpret and challenge consultant inputs:

... the biggest risk from a Local Authority's point of view is not having an ability to challenge, so losing the technical skillset and knowledge to be able to question the advice and recommendations you are being given ... the blurring [between public and private inputs to plan-making] gives them a lack of independence ... [but] as a company that is where we are offering our service by ensuring that we are really trustworthy, that we have our own checks [and] other people that question and validate our work (Consultant Interview 8 , large, nationally-based firm)

\section{Politics and technocratic evidence}

This brings the discussion to the question of how evidence is deployed. For some consultants the planmaking process itself was opaque and they questioned the necessary connection between evidence and policy: 
... in a certain number of Local Authorities there is a strong disconnect between the emerging strategy and the technical evidence base - having worked at a Local Authority for many, many years involved in cross boundary discussions, it is quite clear that politics has a very heavy influence on the plan making process (Consultant Interview 6, multinational firm)

... LPAs do struggle on some of the technical side of things ... they have to make an informed judgement based on their own experiences - I'm not saying that they don't necessarily read it, but I do question at times how much weight is given to external consultants' reports in the context of the other pressures they come under from Elected Members and others (Consultant Interview 2, sole-trader/small firm of associates)

Other private sector respondents identified local government as a "poor client", with LPAs lacking the core skill sets necessary to adequately commission and manage contracts. Although public planners are having to developing new skillsets in order to service a marketised form of planning (e.g. constructing briefs, preparing tenders and managing contracts), in a rare point of disagreement, multiple LPA respondents cited consultants' unrealistic expectations as a cause of friction, suggesting that some "don't get the realities of working in the public sector" (LPA interview 16) and at times require "handholding" (LPA interview 7). However, many of the difficulties encountered appear intrinsic to the plan-making process, rather than necessarily a function of personnel (whether public or private). Interviewees acknowledging "moving goalposts" (LPA Interview 12) of planning regulations, the need for flexibility as the wider evidence base is built-up, and the propensity of local councillors to change their view with prevailing political opinion.

When discussing specific examples of Local Plan inputs, interviewees frequently circled back to the difficulties of reconciling evidence with the views of local politicians. In such cases, both public and private planners returned to framing the latter's inputs as technical artefacts:

... officers informally [have] given consultants the heads up on what things would be politically sensitive but again, we're usually commissions to do a factual piece of work, a piece of technical evidence, so you tend to find that the politics doesn't necessarily cross over into the work that we do (Consultant Interview 12, large, nationally-based firm)

Closer consideration of how evidence is assembled and plans constructed revealed a more subtle process needed to "stitch together the various elements" (LPA Interview 2) into a coherent and "rational' whole: 
... there are ways of writing a report that gives that element of flexibility without it being factually incorrect. So sometimes you are able to present things in a way that is still factually correct but that gives them a bit more scope to interpret ... [for example] housing numbers, it's something that is not black and white, so we can run different scenarios that will give you a range rather than a specific figure ... in relation to housing numbers, it really is linked to economic growth, so it depends on the level of economic growth that the strategy brings about as well, so you tend to find you need that flexibility in these pieces of Local Plan work to allow for that officer to stitch together the right strategy. (Consultant Interview 10, medium-sized firm)

Most LPAs see their Local Plan in a big bubble ...they're very focused on getting it through the examination. I see the picture across the country, and I know that when I see a policy whether it's going to be pulled apart by a planning inspector - I will have a quiet word in the ear of the planning officer, as a critical friend at that point. [One LPA] didn't want me at the examination today because they're trying to blag their Plan through with no representation ... [but] I've written a modification to the plan that they can pull up if the inspector queries it, so they can say "well how about we say this instead?"... Wiggle room is a good way of putting it ... It's about the interpretation of the evidence into particular policies yes, that's where the political work is done. (Consultant Interview 14, sole-trader/small firm of associates)

Public sector interviewees acknowledged that political awareness was an important characteristic for consultants, whilst maintaining a belief in the importance of their independence (for example the benefits of an external report when presenting evidence to Elected Members). In this way consultants are required to be somewhat Janus-faced: both independent of local political considerations whilst simultaneously being sensitive to the same issues. That technical inputs simultaneously open up policy and political alternatives hints at the subtleties of public-private interactions at the local scale. Moreover, the framing of private expertise as merely technical obscures the extent to which consultants not only service the requirements of the public sector but also shape planning practice through the co-construction of policy.

\section{Discussion and Conclusion}

The increasing influence of the consultocracy represents a crucial mechanism by which private business has reached into the state in ways that tie together the interests of the former with the latter $(\mathrm{Li}-$ novski, 2018). Existing literature in the UK has has established that austerity, successive rounds of re- 
form, and the fragmentation of planning into discrete, deliverable tasks is opening market opportunities for consultants and driving diverse outcomes in English planning policy (Parker et al., 2018; Raco, 2018). It is clear that local planning policy in England is underpinned by such public-private entanglements, however the dynamism and frequency of such interactions make it increasingly difficult to discern the roles, motivations and influence of local actors. The findings of this study have established that LPAs in England have entered a relationship of critical dependence with the private sector in relation to the production of local planning policy. All bar one of the public planners interviewed considered it inconceivable that a Local Plan could be produced without external capacity and expertise. This is not inherently problematic in itself - the private sector has long contributed to the planning project but such dependency does require sustained, critical attention as the public-private interface continues to take on greater meaning within the political-economic context of state retrenchment and associated processes of commercialisation and wider privatization. Recognizing the heterogeneity of the consultancy market is central to nuancing this analysis, as a range of experiences and motivations are being subsumed within 'public' planning policy.

The findings of this study suggest that the inherent dynamism of the market may add to the resilience of the planning system by providing much needed capacity as well as anticipating, interpreting and advising on regulatory reform. This would appear highly necessary at a time of continual reform and fragmentation (see Parker et al., 2018), however we should be wary of 'bracketing out' consultants from the reproduction of complex and turbulent policy landscapes (Prince, 2012). Any added resilience needs to be weighed against the loss of both specialist knowledge (episteme) and tacit knowledge (techne) within LPAs, both of which are central to the re-production of public-private dependencies. The loss of episteme undermines the ability of government actors to recognize sub-standard advice or rent-seeking behaviours in specialist areas of evidence production. Just as problematically, the loss of techne may preclude the ability of LPAs interpret such knowledge inputs and assemble them into coherent plans. The insinuation of private sector expertise into public policy production simultaneously undermines the capacity and expertise within local government, whilst servicing the same weaknesses. 
This paper has considered consultants' roles in local plan-making, which is only one of the multiple roles consultants play at all spaces and levels of the UK planning system. The public-private interface is inherently difficult to conceptualize due its dynamism and the necessity to remain faithful to local context and specificities. However there remains a need to shift away from teleological explanations of private expertise that pervade both practitioner and academic discourse, including many of the practitioner views discussed above. Such explanations are driven toward solutions, continuing influential strands of thought around 'deliverology', by framing consultant inputs as apolitical, and techno-rational solutions to functionalist problems. This situation obfuscates the inherently political nature of planning that has been established for some time (Altshuler, 1965), and therefore has avoided uncovering the normative and political values at play.

When identifying the rationales for consultant use, public planners placed considerably more emphasis on instrumental and epistemological rationales (particularly achieving cost-efficiency and the need for specialist expertise), over political ones such as independence when reporting to local politicians or in insulating local authorities from criticism at examinations. Yet interviewees also highlighted consultant inputs as providing open ended reports and providing policy alternatives based on their evidence, the importance of local knowledge and ongoing relationships as part of their "offer", and providing "strategic thinking" to embattled LPAs. Such characteristics subvert traditionally held views of consultants, and point to the co-construction of local planning policy, and the political work that is undertaken by public-private entanglements. Moreover, the opening up of market opportunities within the local state indicates a need to move towards greater understanding of the state's role in co-constructing the (planning) consultancy market in a Polanyian sense (Polanyi, 2001[1944]). This should build on the recognition that individuals continually broker market relations, shaping professional practice itself, and should range from the micro-level of policy creation (i.e. the promotion or negation of policy alternatives) to the more abstracted role in constructing the "realm of possibilities" and the blurring of public and private interests (Linovski, 2018: 28). This task is central to understanding contemporary 
practice as planning knowledge is increasingly mediated and organised by the market, arguably circumscribing the ability of the state to fulfil its traditional, if not unproblematic, role to promulgate the public interest.

Axiomatically, the exchange relationships operating between the (local) state and private actors are contingent and mutable, but crucially they appear to be increasingly asymmetrical with LPAs dependent on external capacity and advice. Widening market opportunities and an enfeebled local state has created greater leverage for the private sector with the result that local government remains simultaneously powerful and powerless in procurement processes. Reflecting findings concerning the influence of management consultants, the necessity of external capacity and expertise described by interviewees points to an unproblematized "belief in the efficiency of particular practices or solutions, rather than any proven efficiency" (Armbrüster, 2006: 7) with troubling implications for the wider governance of planning. This underscores how the dependencies arising between local planning apparatus and consultants are still not well understood, sufficiently proven, nor typically open to public scrutiny.

\section{References}

Allmendinger, P. (2016) 'Contemporary spatial governance', in Bevir, M. (ed.) Governmentality after Neoliberalism, London, Routledge, pp.16-30.

Altshuler, A. (1965) The City Planning Process, Ithaca, Cornell University Press.

Audit Commission (2006) The planning system: Matching expectations and capacity, London, Audit Commission.

Armbrüster, T. (2006) The Economics and Sociology of Management Consulting, Cambridge, Cambridge University Press.

Birch, K. and Siemiatycki, M. (2016) 'Neoliberalism and the geographies of marketization: The entangling of state and markets', Progress in Human Geography, 40(2): 177-198.

Brown, C., Claydon, J. and Nadin, V. (2003) 'The RTPI's Education Commission: context and challenges', Town Planning Review, 74(3): 333-345.

Brudell, P. (2014) 'The role of private consultancies in neoliberal urban regeneration', in MacLaren, A. and Kelly, S. (eds.) Neoliberal Urban Policy and the Transformation of the City, Basingstoke, Palgrave Macmillan, pp.233-246. 
Campbell, H., and Marshall, R. (2002) 'Values and professional identities in planning practice', in Allmendinger. P. and Tewdwr-Jones, M. (eds.) Planning Futures, London, Routledge, pp.65-92.

Clarke, J. and Newman, J. (1997) The Managerial State, London, Sage.

Christensen, T. and Laegreid, P. (2007) 'The whole-of-government approach to public sector reform', Public Administration Review, 67(6): 1059-1066.

Dalton, L.C. (1986) 'Why the rational paradigm persists - The resistance of professional education and practice to alternative forms of planning', Journal of Planning Education and Research, 5(3): 147153.

Davoudi, S. and Healey, P. (1990) Using Planning Consultants: The Experience of Tyne and Wear Development Corporation, Newcastle, University of Newcastle Upon Tyne.

Dear, M. (1989) 'Survey 16; Privatization and the rhetoric of planning practice', Environment and Planning D: Society and Space, 7(4): 449-462.

Diefenbach, T. (2009) 'New Public Management in public sector organisations: the dark sides of managerialistic 'Enlightenment', Public Administration, 87(4): 892-909.

Fordham, R. (1990) 'Planning consultancy: can it serve the public interest?', Public Administration, 68(2): 243-248.

Froud, J., Johal, S., Moran, M. and Williams, K. (2017) 'Outsourcing the state: New sources of elite power', Theory, Culture \& Society, 34(5-6), 77-101.

Grijzen, J. (2010) Outsourcing planning: what do consultants do in regional spatial planning in the Netherlands, Amsterdam, Amsterdam University Press.

Gunn, S. and Vigar, G. (2012) 'Reform processes and discretionary acting space in English planning practice, 1997-2010', Town Planning Review, 83(5): 533-552.

Healey, P. (2007) Urban Complexity and Spatial Strategies: towards a relational planning for our times, London, Routledge.

Higgins, M. and Allmendinger, P. (1999) 'The changing nature of public planning practice under the New Right: the legacies and implications of privatization', Planning Practice and Research, 14(1): 39-67.

Hood, C. and Jackson, M.W. (1991) Administrative Argument, Aldershot, Dartmouth.

Inch, A., Tait, M. and Wargent, M. (forthcoming) 'Serving the public interest? Towards a genealogy of private sector planning expertise', International Journal of Urban and Regional Research.

Jordan, B. (1989) The Common Good: Citizenship, Morality and Self-Interest, Oxford, Basil Blackwell.

Linovski, O. (2016) 'Politics of Expertise: Constructing Professional Design Knowledge in the Public and Private Sectors', Journal of Planning Education and Research, 36(4): 451-464. 
Linovski, O. (2018) 'Shifting agendas: private consultants and public planning policy', Urban Affairs Review, published online 6 February 2018.

Linovski, O. (2019) 'Shareholder as client: Firms, markets, and the new business of planning', Journal of Urban Affairs, published online 24 January 2019.

Loh, C.G. and Norton, R.K. (2013) 'Planning consultants and local planning', Journal of the American Planning Association, 79(2): 138-147.

Loh, C.G. and Arroyo, R.L. (2017) 'Special ethical considerations for planners in private practice', Journal of the American Planning Association, 83(2): 168-179.

Lord, A. and Hincks, S. (2010) 'Making Plans: The Role of Evidence in England's Reformed Spatial Planning System', Planning Practice and Research, 25(4): 477-496.

Lord. A. and Tewdwr-Jones, M. (2014) 'Is Planning "Under Attack"? Chronicling the Deregulation of Urban and Environmental Planning in England', European Planning Studies, 22(2): 345-361.

Mazzucato, M. (2014) The Entrepreneurial State, London, Anthem Press.

McCann, E. (2001) 'Collaborative Visioning or Urban Planning as Therapy? The Politics of PublicPrivate Policy Making', The Professional Geographer, 53(2): 207-218.

McCann, E. and Ward, K. (eds.) (2011) Mobile urbanism: cities and policy-making in the global age, Minneapolis, University of Minnesota Press.

Mitchell, V. (1995) 'A survey of chief planning officer's attitudes to planning consultants', International Journal of Public Sector Management, 8(1): 20-31.

Momani, B. and Khirfan, L. (2013) 'Explaining the use of planning consultants in Ontario cities', $\mathrm{Ca}$ nadian Public Administration, 56(3): 391-413.

NAO [National Audit Office] (2018) Financial sustainability of local authorities 2018, HC 834, London, NAO.

NAO (2019) Planning for new homes, HC 1923, London, NAO.

Newman, J. (2014) 'Landscapes of antagonism: Local governance, neoliberalism and austerity', Urban Studies, 51(15): 3290-3305.

Ormerod, E. and MacLeod, G. (2018) 'Beyond consensus and conflict in housing governance: Returning to the local state', Planning Theory, published online 1 August 2018.

Parker, G., Lynn, T. and Wargent, M. (2015) 'Sticking to the script? The co-production of neighbourhood planning in England', Town Planning Review, 86(5): 519-536.

Parker, G., Street, E., Raco, M. and Freire-Trigo, S. (2014) 'In planning we trust? Public interest and private delivery in a co-managed planning system', Town and Country Planning, 83(12): 537-540.

Parker, G., Street, E. and Wargent, M. (2018) 'The rise of the private sector in fragmentary planning in England', Planning Theory \& Practice, 19(5): 734-750. 
Parker, G., Street, E. and Wargent, M. (2019) 'Advocates, advisors and scrutineers: the technocracies of private sector planning in England', in Raco, M. and Savini, F. (eds.) Planning and Knowledge: How New Forms of Technocracy Are Shaping Contemporary Cities, Bristol, Policy Press, pp.157-167.

Polanyi, K. (2001) [1944] The Great Transformation: the political and economic origins of our time, Boston, Beacon Press.

Prince, R. (2012) 'Policy transfer, consultants and the geographies of governance', Progress in Human Geography, 36(2): 188-203.

Raco, M. (2013) 'The new contractualism, the privatization of the welfare state, and the barriers to open source planning', Planning Practice and Research, 28(1): 45-64.

Raco, M. (2018) 'Private consultants, planning reform and the marketisation of local government finance', in Ferm, J. and Tomaney, J. (eds.) Planning Practice, London, Routledge, pp.123-137.

Raco, M., Street, E. and Freire-Trigo, S. (2016) 'The New Localism, anti-political development machines, and the role of planning consultants: lessons from London's South Bank', Territory, Politics, Governance, 4(2): 216-240.

Read, D.C. and Leland, S.M. (2011) 'Does sector matter? An analysis of planners' attitudes regarding politics and competing interests in the planning process', The American Review of Public Administration, 41(6), 639-653.

Reade, E. (1987) British Town and Country Planning, Milton Keynes, Open University Press.

RTPI [Royal Town Planning Institute] (2019) The UK Planning Profession in 2019, London, RTPI.

Saint-Martin, D. (1998) 'The new managerialism and the policy influence of consultants in government: An historical-institutionalist analysis of Britain, Canada and France', Governance, 11(3): 319356.

Saint-Martin, D. (2000) Building the New Managerialist State: Consultants and the Politics of Public Sector Reform in Comparative Perspective, Oxford, Oxford University Press.

Savini, F. and Raco, M. (2019) 'The rise of a new urban technocracy', in Raco, M. and Savini, F. (eds.) Planning and Knowledge: How New Forms of Technocracy Are Shaping Contemporary Cities, Bristol, Policy Press, pp.3-17.

Scott, T.A. and Carter, D.P. (2019) 'Collaborative governance or private policy making? When consultants matter more than participation in collaborative environmental planning', Journal of Environmental Policy \& Planning, 21(2); 153-173.

Slade, D., Gunn, S. and Schoneboom, A. (2019) Serving the public interest? The reorganisation of UK planning services in an era of reluctant outsourcing, London, RTPI.

Steele, W. (2009) 'Australian urban planners: hybrid roles and professional dilemmas?', Urban Policy and Research, 27(2): 189-203.

Stapper, E.W., Van der Veen, M. and Janssen-Jansen, L.B. (2019) 'Consultants as intermediaries: Their perceptions on citizen involvement in urban development', Environment and Planning C: Politics and Space, published June 5, 2019. 
Tait, M. (2016) 'Planning and the public interest: still a relevant concept for planners?', Planning Theory, 15(4): 335-343.

Vogelpohl, A. (2018) 'Consulting as a threat to local democracy? Flexible management consultants, pacified citizens, and political tactics of strategic development in German cities', Urban Geography, 39(9): 1345-1365.

Wargent, M., Parker, G. and Street, E. (forthcoming) 'Private expertise and the spatial reorganisation of planning in England', in Jonas, A. et al. (eds.) Handbook on the Changing Geographies of the State: New Spaces of Geopolitics, Cheltenham, Edward Elgar.

Ylönen, M. and Kuusela, H. (2019) 'Consultocracy and its discontents: A critical typology and a call for a research agenda', Governance, 32(2): 241-258.

Zanotto, J. (2019) 'Detachment in planning practice', Planning Theory \& Practice, 20(1): 37-52. 